\title{
Efficiency of the Method of Student Thematic Online Debates in the Development of Professional Competences in Future Specialists
}

\author{
NATALIIA H. SHARATA, TETIANA V. BEREZOVSKA, TETIANA P. KRAVCHENKO \\ Department of Ukrainian Studies, Faculty of Accounting and Finance \\ Mykolayiv National Agrarian University, Mykolaiv \\ UKRAINE
}

\begin{abstract}
The transition to distance learning because of the COVID-19 pandemic has led teachers to adapt effective teaching methods to distance education. Theoretical analysis of scientific works allowed determining that student debates have significant potential for the development of critical thinking, communication skills. The aim of the study was to test the effectiveness of the method of student thematic online debates in the development of professional competencies in future specialists. In the experimental study, several complementary techniques were used to determine the level of future specialists' professional competence. The reliability of the obtained conclusions on the basis of the used methods was ensured by comparing the data obtained by each method, as well as the representativeness of the sample size and statistical significance of the experimental data. It is determined that the following competencies can be developed in students through the method of student thematic online debates: readiness to work in a team, ability to generalize, analyse and adequately perceive information, ability to communicate according to language norms, reasoned and clearly build oral and written speech. The study allowed determining that there are certain methodological features of using the method of student thematic online debates in the distance educational process. The method of debate is an effective approach to the organization of online learning, which allows obtaining not only theoretical knowledge, but also gives the possibility of applying them in professional activities in the future. Proof of the effectiveness of the proposed model of using debate within distance learning is confirmed by the unequivocally positive dynamics in the experimental group to improve the Value-orientation criterion, Cognitive criterion Communicative-activity criterion (in particular, at a high level of $13.79 \%, 7.38 \%, 11.56 \%$ respectively). The novelty of the presented scientific intelligence in the experimental study of the potential of online debates for students of agricultural universities, but with the potential to adapt the presented model of organization of the pedagogical environment for students of other specialties. The research materials can be used by teachers in the development of distance online courses, heads of distance learning coordination departments in higher educational institutions. The prospect of further research is studying the effectiveness of thematic online debates to increase the level of internal learning motivation in future specialists.
\end{abstract}

Key-Words: - distance learning, online debate, debate method, professional training, future specialists.

Received: May 25, 2021. Revised: November 10, 2021. Accepted: December 18, 2021. Published: January 13, 2022.

\section{Introduction}

The COVID-19 pandemic has brought significant changes to education worldwide during 2020. In Ukraine, the readiness for this process was different. There were various technical problems, such as the lack of Internet connection, computers or teaching materials on the network, and most importantly the unpreparedness of teachers for distance learning. The transition to distance learning has led teachers to adapt effective teaching methods to distance education. The search for educational technologies and methods aimed at the development of communicative competence in the modern approach to the training of future specialists in all majors is relevant.
Communicative competence ensures the success of the communicative activity of a specialist through the language means, in accordance with the purpose and situation of communication within any field of activity. The concept of communicative competence is a combination of all components that create communication situations. This is the necessary knowledge and skills for students to help understand and create their own programmes of the language behaviour.

The method of debate deserves special attention in the development of communicative competence. The relevance of this method is due to the requirements of modern society. Nowadays, it is important to reveal the individual abilities of a student as much as possible and to form a 
professionally and socially competent, mobile personality on this ground. The future specialist must be able to make professional social choices and be responsible for them.

The method of debate is universal in nature, as it can be filled with any content and used in the study of any subject. Debate as a technique and a method has its own characteristics. This is not just a free exchange of views on any issue, but a formalized dispute according to certain rules.

Thus, the urgent problem of higher education is the need to find effective teaching methods in distance education. This is due to the importance of developing communication skills of future specialists in any field of activity, the ability to defend and argue their own opinion on professional issues.

The aim of this study is to substantiate and experimentally test the effectiveness of the method of student thematic online debates in the development of professional competencies in future specialists. The main objectives that follow from the topicality of the research and need to be addressed are:

1) study whether the method of student thematic online debates is effective for the development of professional competencies in future specialists;

2) identify which competencies can be strengthened using the method of student thematic online debates;

3) describe the peculiarities of using the method of student thematic online debates in the distance educational process.

\section{Literature Review}

Online education is a growing field of educational services, in 2016 more than $30 \%$ of college students studied at least one online course [1]. These indicators and the further development of this field of education have increased and will continue to grow during the coronavirus pandemic as well as the whole area of social relations and mechanisms of social niche functioning [2-6]. Studies have shown that teachers use traditional teaching methods in the distance teaching without adapting them to the conditions of distance education, which significantly reduces the effectiveness of learning [7]. Due to the peculiarities of distance education, teachers do not purposefully develop the communicative competence in future specialists, do not know which methods are effective [8, 9]. Communicative competence is a professional quality of a modern specialist that provides the ability to communicate competently and effectively, succeed in professional activities, take a professional dialogic position, formulate their own judgments and argue them. Studies $[10,11]$ note that the effectiveness of the development of communication skills in future specialists during distance learning has decreased significantly.

Debate is a well-known pedagogical technique that is used to encourage discussion, motivate students, and this leads to a deeper understanding of the subject [12]. Author [13] note that online discussions can be part of a transformational learning process to improve their knowledge on a particular topic through social learning. Debate is often used as a learning strategy in high school, but little is known about its use in online learning environments [14]. Debates allow to comprehend the existing and gain new emotional, communicative experience [15]. This method develops students' skills necessary for effective communication in any field of human activity [16], as well as in the future professional activity.

There are several formats of the Debate game: managerial format, parliamentary debate, legal debate, Karl Popper debate, political debate, Russian format, Lincoln-Douglas debate, open debate, scientific debate, presidential format (American format). Their difference is the number of participants, rules and goals of the game [17]. Authors [18] divides the debate into two types: formal and informal. Their difference is that the former ones have no rules, and the latter provide clear regulation. Most often, the first option is used in professional education [19].

Scholars [20] believe that debate is effective in acquiring new knowledge and skills, such as communication, critical thinking, teamwork, which can be related to processes consistent with adult learning, motivational, reflective and social theories of learning. Authors [21] compared the effectiveness of three different types of online debates (open discussion, debate, and case-by-case discussion) to improve critical thinking skills. Authors [22] found that debate improved students' achievement in critical thinking. Another study, [23], covered online discussion assignment in a graduate program on leadership and found that students who studied online had a higher level of participation and success (that is, better performance and higher grades) than students in traditional system.

Author [24] also noted that online debates last longer, providing students with the opportunity to explore a topic differently - and probably more deeply - than personal discussions. The author concludes that online debates can be effective in 
increasing engagement in course discussion and encouraging more complex or in-depth reflection on issues. Authors [25] found that deliberate planning of debates (e.g., role assignments, expectations) helped students prepare more thoughtful and critical arguments. Authors [25] also noted the flexibility of online debate, which allows students and teachers to have time to communicate and reflect on the material. Authors [25] found that the activities of interprofessional clinical debates had a positive impact on physicians and pharmacy students, and improved attitudes toward interprofessional teams.

From the literature review, it follows that debate as a method of learning in itself has a significant potential to enhance the activities of students, stimulating the motivational mechanisms of their learning activities, a conscious attitude to the process of acquiring knowledge. In addition, it is the key to the subject-subject model of building relationships between all participants in the educational process. Analysis of previous research on the use of debate as a method of teaching online has shown that determination and courage in expressing their views, willingness to argue their own position in various life situations, maximum tolerance in speech and behavior (note that this is the key to quality classical debates sample) will be formed only if the use of active dialogic learning technologies. And debate is just a variant of dialogic interaction of participants of educational process. In addition, the whole world today is built on the principles of tolerance and dialogue, but constructive controversy, discussion in order to resolve topical issues by agreement, rather than force (physical, military, harmful). The search for consensus and compromise in society remains the prerogative of the people. Therefore, the debate is now particularly important for each country. It is in the form of debates that the parliaments of traditional democracies work, debates are elements of the election campaign, and the subject of debate is studied in the most prestigious educational institutions in the whole world [9-11, 13].

Thus, based on the analysis of literature sources and certain advantages, we advanced the hypothesis that using the method of student thematic online debates can have a positive impact to increase the level of professional competencies of future specialists.

\section{Methods and Materials}

The experimental study involved several complementary techniques to determine the level of communicative competence in future specialists: the method of Self-Assessment of Communicative Competence; Incomplete Sentence; Delphi technique; Ask Questions to the Text (S.K. Tivikova); methods of assessing communication and organizational skills (V.V. Syniavskyi, B.A. Fedorishchin).

The reliability of the obtained conclusions on the basis of the used methods was ensured by comparing the data obtained by each method, as well as the representativeness of the sample size and statistical significance of the experimental data. Research methods adequate to the subject of the research were used.

A correlation analysis was performed to process the results of the study, using a parametric method of comparing two samples - Student's t-test for independent samples. Statistical data processing was performed using SPSS 10 for Windows, Excel.

The subjects of the study were students majoring in 071: Accounting and Taxation, 072: Finance, Banking and Insurance, 073: Management, aged 1719 , who are studying in the 1st and 2nd year fulltime. The Mykolayiv National Agrarian University was chosen as the experimental base of the research, 1,128 students made up the general population. After calculating the size of the required (representative) sample using an online calculator (with parameters: confidence probability - 85\%, error - 10\%), the size of a valid sample was 50 people. This number was the starting point for the formation of the experimental group (EG) $(n=24)$ and the control group (CG) $(n=26)$.

A group of independent experts was formed to assess the success of student interaction in the online learning format, who also worked with students in a conference format on the Google Meet platform (with microphones and cameras turned off, as well as nicknames instead of real names). There were six experts. They were the rector of the university, two teachers of the Department of Ukrainian Studies, the head of the Department of Economic Theory and Social Sciences, the member of the Department of Public Relations of the Mykolayiv City Council, two graduate students majoring in 051 Economics and 073 Management.

The criteria for determining the level of communicative competence of the future specialist were identified: value-oriented, cognitive, communicative-activity. The value-orientation criterion includes motives, values related to the interaction of students, their desire to engage in communication, understanding the importance of communication for the student's personality and their future professional activity. Cognitive criterion is associated with knowledge of ways of 
communicative activity. The communicativeactivity criterion provides for the developed communicative competence and the ability to use it in accordance with the conditions of professional and life communication.
There are three levels of communicative competence of future specialists: low, medium, high. The description of each level is presented in Table 1.

Table 1. Levels of communicative competence of future specialists

\begin{tabular}{|c|c|c|c|}
\hline \multirow[t]{2}{*}{ Criterion } & \multicolumn{3}{|l|}{ Level } \\
\hline & Low & Medium & High \\
\hline $\begin{array}{l}\text { Value- } \\
\text { oriented }\end{array}$ & $\begin{array}{l}\text { Passive, participates in the } \\
\text { debate only after repeated } \\
\text { instructions from the teacher } \\
\text { or groupmates. Prepares for } \\
\text { the debate only after repeated } \\
\text { reminders. Not interested in } \\
\text { other people's views. } \\
\text { Demonstrates unfriendly } \\
\text { attitude towards peers during } \\
\text { the conflict. }\end{array}$ & $\begin{array}{l}\text { Willingly contacts with } \\
\text { groupmates, if interesting activities } \\
\text { are offered. If necessary, he/she } \\
\text { can express himself/herself and } \\
\text { defend his/her point of view, but } \\
\text { prefers to remain an observer. } \\
\text { Shows interest in another point of } \\
\text { view only during the debate. Does } \\
\text { not always maintain a friendly } \\
\text { attitude to classmates in conflicts of } \\
\text { interest. }\end{array}$ & $\begin{array}{l}\text { Willingly speaks, helps other } \\
\text { participants in the debate. Actively } \\
\text { prepares for debates, selects } \\
\text { information and arguments from } \\
\text { the literature and the Internet. } \\
\text { Respects other people's views. } \\
\text { Maintains a friendly attitude to } \\
\text { groupmates in case of conflict of } \\
\text { interest. }\end{array}$ \\
\hline Cognitive & $\begin{array}{l}\text { Hesitates when identifying the } \\
\text { main idea in the text, does not } \\
\text { use scientific terms and } \\
\text { concepts and their definition. }\end{array}$ & $\begin{array}{l}\text { Separates basic information } \\
\text { from secondary, but hesitates } \\
\text { to identify the main idea, uses } \\
\text { some scientific terms and } \\
\text { loncepts, as well as their } \\
\text { definitions. }\end{array}$ & $\begin{array}{l}\text { Identifies the main idea in the } \\
\text { text, distinguishes between basic } \\
\text { and secondary information. } \\
\text { Fluent in the text, actively uses } \\
\text { scientific terms and concepts, as } \\
\text { well as their definitions. }\end{array}$ \\
\hline $\begin{array}{l}\text { Communicativ } \\
\text { activity }\end{array}$ & $\begin{array}{l}\text { Does not identify mistakes in } \\
\text { his/her oral and written } \\
\text { language and does not try to } \\
\text { correct them. Uses everyday } \\
\text { language during the debate. } \\
\text { The speech is dominated by } \\
\text { short answers. Does not see } \\
\text { causal relationships (chains). } \\
\text { Can't pick arguments. }\end{array}$ & $\begin{array}{l}\text { Does not always see mistakes in } \\
\text { oral and written language, but he } \\
\text { corrects them when remarks are } \\
\text { made. Tries to use scientific terms } \\
\text { in his/her answers, but the } \\
\text { language is incoherent. The speech } \\
\text { is dominated by short answers, } \\
\text { gives full reasoned answers under } \\
\text { the teacher's guidance. Builds } \\
\text { causal chains, selects one or two } \\
\text { arguments to defend the thesis with } \\
\text { the teacher's help. }\end{array}$ & $\begin{array}{l}\text { Independently finds errors in } \\
\text { his/her oral and written language } \\
\text { and corrects them. When } \\
\text { answering, he/she uses scientific } \\
\text { language, the language is } \\
\text { coherent. Gives full detailed } \\
\text { answers, provides evidence of the } \\
\text { correctness of his/her answers. } \\
\text { Confidently builds a causal chain. } \\
\text { Builds a system of arguments in } \\
\text { defence of his/her thesis }\end{array}$ \\
\hline
\end{tabular}

The experimental research was carried out in the study of the subjects of general professional training Ukrainian Language (by specialization), History of Ukrainian Culture, Religious Studies, History of Ukraine, Culturology. In addition, the students' work was observed within the framework of studying the courses "Plant Production Management" and "History of Economics and Economic Thought" (first-year students), "Macro and Microeconomics" (second-year students). The study was organized in three stages during 20202021. The first - theoretical and design stage (January-May 2020) — involved the selection, substantiation and theoretical understanding of the problem and research topic, as well as the experience of implementing distance education in the period before the pandemic. The programme and methodology of the experiment and working programmes of academic subjects were developed using the method of thematic online debates. Preexperimental measurement was made.

Within the framework of the organization of training, the students of the control group studied according to the traditional mixed method, which provided for the minimum adaptation of traditional classroom types of work to the conditions of distance learning. Instead, educational communicative methods were used to teach the students of the experimental group: a monologue of the student with the following discussion, presentation + speech support, discussion, problem conversation, etc.

In addition, before the experiment, the students of the experimental group listened to a special theoretical and practical blocks. Block 1 (Why debate? Educational debates as a multifunctional pedagogical technology. Debate and development of critical thinking. / The essence and main elements of 
the debate. Why is debate an interaction, not a confrontation?). Block 2 (Basics of argumentation. Effective refutation. The role of questions in the debate. / We pump up the oratorical muscles. How to teach students to build persuasive speech. / Knowledge - in action: debate sparring). Block 3 (Main debate formats and their features. Simulation of a debate game in the format of Karl Popper, its analysis. / And who are the judges: the practice of judging in debates). Block 4 (We gather like-minded people. Practical possibilities of using debate technology in the educational space). It was based on the principles of Critical Thinking Educational Platform (https://www.criticalthinking.expert/).

The second - experimental stage (JuneDecember 2020) — involved a pedagogical experiment, online classes in the experimental group were intensified using the method of student thematic debates. Debates were held with students in practical online classes, topics and roles were given to students in advance in order to provide them with quality training, teachers of academic subjects provided guidance for the debate. An experimental measurement was performed at this stage. The third stage - generalization (JanuarySeptember 2021) - provided for the processing of measurement data, interpretation of statistical indicators. The obtained results were compared with the expected and previous research on the selected problem, recommendations were developed and the results of the study were documented at this stage.

\section{Results}

The next task of our study was to carry out preexperimental measurement. In order to test the effectiveness of the method of student thematic online debates, it was necessary to determine the initial level of communicative competence of future specialists according to the methods specified in the methodological background of the study.

Analysis of the results on the level of communicative competence of students of agricultural university at the stage of the observational experiment showed that of the 50 people who participated in Self-Assessment of Communicative Competence, a low level was found in $51 \%$ of students; medium level - in $31 \%$; high level - in $12 \%$ of students. In the context of this method, students assessed their level of communicative competence on a 9-point scale from 1 to 9. The lowest score based on students' selfesteem was "set" by the following methods of action in communicative competence: readiness to use one of the foreign languages (OK-2); ability and readiness for public speeches, argumentation, discussion and controversy (OK-12); ability and willingness to use basic techniques, methods and means of obtaining, storing, processing information, willingness to use a computer as a means of working with information (OK-11). In addition, the students tested their communicative skills online by the resource "Communication Skills Assessment Test Yourself!" (https://www.findcourses.com/). Its structure is organized over testing general communicative skills and professional communicative skills. For example, questions like "It's okay to interrupt others if you feel passionately about the topic of discussion" with variants of answer "Strongly agree" / "Agree" / "Neither agree or disagree" / "Disagree" / "Strongly disagree" perfectly fits our theme and vector of research. Besides, this kind of work integrated also a foreign language communicative context that is strongly demand in the context of nowadays private life, studying and professional activity.

Based on the summative stage of the pedagogical experiment, a conclusion was made about the need to develop communicative competence based on the use of online debate methods. Teachers do not purposefully develop communicative competence in the course of distance learning during the pandemic referring to the lack of time and conditions of distance learning, do not consider their subject decisive for the development of such competence, do not fully use the arsenal of innovative teaching methods in distance education.

Analysis of the results of the state of the students' communicative competence shows that it is insufficiently developed for future professional activity and individual development. They have a weak idea of the culture of communication, organizational and communication skills, have difficulty regulating their behaviour, do not fully seek to develop the qualities necessary for full communication. This is especially difficult under the conditions of unrealistic and remote communication. Students feel trapped in the course of interpersonal interaction, public speaking, rarely engage in dialogue, are afraid to speak during online classes, as a rule, interaction with groupmates is template and formal. Teachers do not sufficiently use interactive teaching methods (business and roleplaying games, discussions, trainings, case studies, situation analysis, etc.) during online classes, which confirmed the need to develop a methodology for the development of communicative competence based on thematic online debates. 
Determining the levels of communicative competence of future specialists based on the application of the method of thematic online debates in the experimental stage are shown in Table 2. Table 3 shows an increase in communicative competence of future specialists.

Table 2. The results of a one-factor CFA model applied to the test distributed by ethnic groups and social groups

\begin{tabular}{|l|c|c|c|c|c|c|}
\hline Levels & \multicolumn{2}{|c|}{ Value-orientation criterion } & \multicolumn{2}{c|}{ Cognitive criterion } & \multicolumn{2}{c|}{ Communicative-activity criterion } \\
\hline & $E G$ & $C G$ & $E G$ & $C G$ & $E G$ & $C G$ \\
\hline High & $29.17 \%$ & $15.38 \%$ & $45.84 \%$ & $38.46 \%$ & $50.00 \%$ & $38.46 \%$ \\
\hline Medium & $54.16 \%$ & $34.62 \%$ & $45.84 \%$ & $42.31 \%$ & $37.50 \%$ & $42.31 \%$ \\
\hline Low & $16.67 \%$ & $50.00 \%$ & $8.32 \%$ & $19.23 \%$ & $12.50 \%$ & $19.23 \%$ \\
\hline
\end{tabular}

Table 3. The descriptive statistics and coefficients of reliability based on the Cronbach's reliability coefficient and composite reliability coefficients and drawn from ethnic groups and social groups

\begin{tabular}{|l|c|c|c|c|c|c|}
\hline \multicolumn{1}{r|}{ Levels } & \multicolumn{2}{|c|}{ Value-orientation criterion } & \multicolumn{2}{c|}{ Cognitive criterion } & \multicolumn{2}{c|}{ Communicative-activity criterion } \\
\hline & $E G$ & $C G$ & $E G$ & $C G$ & $E G$ & $C G$ \\
\hline High & $8.33 \%$ & $3.85 \%$ & $12.50 \%$ & $3.85 \%$ & $25.00 \%$ & $3.85 \%$ \\
\hline Medium & $25.00 \%$ & $0 \%$ & $0 \%$ & $0 \%$ & $-16.67 \%$ & $-3.85 \%$ \\
\hline Low & $-33.33 \%$ & $-3.85 \%$ & $-12.50 \%$ & $-3.85 \%$ & $-8.33 \%$ & $0 \%$ \\
\hline
\end{tabular}

From Table 2 and Table 3, which follows from it, we can trace the positive dynamics in the development of communicative competencies of students in the experimental group. Thus, the experiment managed to improve the communicative-activity criterion the most (since the respondents were students of agricultural universities, for us this criterion was the most important - given the pragmatic purpose of using speech by these students as a tool of influence and self-realization in future professional activities). Thus, according to the Communicative-activity criterion, the increase was as much as $25 \%$. It is noteworthy that the increase at a high level meant a significant decrease in the percentage distribution in the risk zone (especially the low level of formation of communicative competencies). For example, due to the increase in the quality of the value-orientation criterion at the middle and high levels, the low level of this criterion in the experimental group became lower by as much as $33.33 \%$. Such dynamics can be considered as a considerable achievement and the main indicator of efficiency of the applied techniques.

As for the control group, although in the ratio of high / low level of communicative competence the dynamics here is also positive, but not as clearly defined as in the students of the experimental group. The communicative-activity criterion also improved the most within this group. This testifies to the generally correct pedagogical approach to the organization of students' education in the disciplines indicated earlier in the section "Materials and methods". However, the comparison of the results with the data of the respondents of the experimental group is the best evidence in favor of the method of using online debates to improve communicative competencies better in the shortest possible time.

In addition, the results are drafted in a comparing format in the figures below by criteria of the estimated communicative competences (Figs. 1-3).

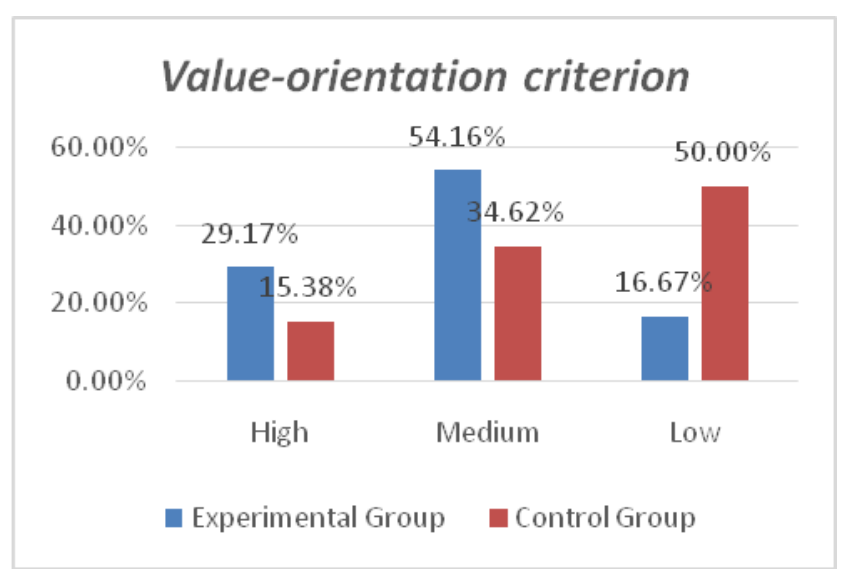

Fig. 1: Value-orientation criterion: comparison of the results of the experimental and control groups 


\section{Cognitive criterion}

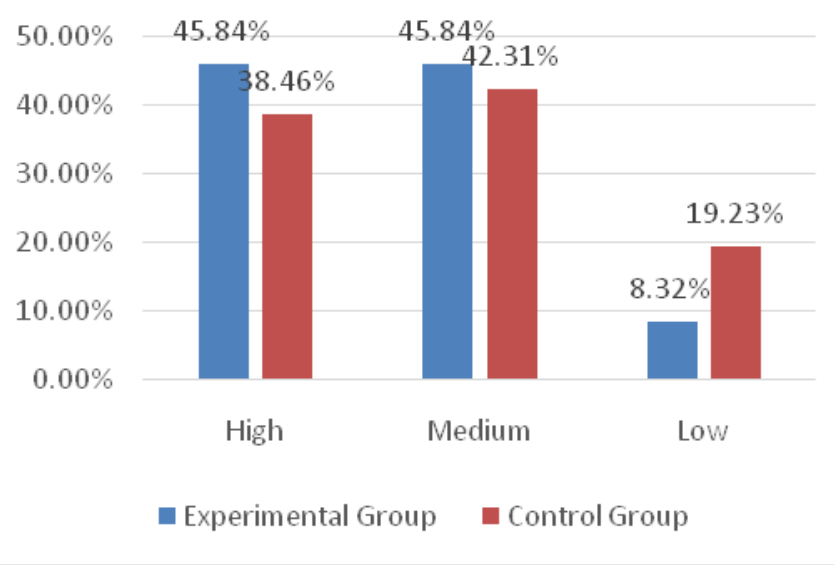

Fig. 2: Cognitive criterion: comparison of the results of the experimental and control groups



Fig. 3: Communicative-activity criterion: comparison of the results of the experimental and control groups

Analysis of the results of developing communicative competence in future specialists through thematic online debates suggests that the share of students with high and medium understanding of the importance and value of communicative competence (value-oriented criterion) significantly increased in the course of formative experiment. There were significant changes in the cognitive criterion that describes students' knowledge of the essence of communicative competence. The share of students with a high level of communicative-activity criteria also increased compared to the control group: (high level: EG - 50.00\%; CG - 38.46\%), which indicates the ability to dialogue, cooperate, join the group activity. Analysis of the data shows that there were no significant changes in the distribution of students according to the selected criteria in the control group. If compare the results of both groups with concerning the high criterion, it is obvious that the difference of $13.79 \%, 7.38 \%, 11.56 \%$ according to the value-orientation, cognitive and communicative-activity criteria, respectively, clearly indicate in favor of the online method debates within distance learning.

Tables 4-6 show the results of checking the samples for normality for three different criteria. The analysis of the given data showed that all or the majority of conditions necessary to consider distribution close to normal are fulfilled in all considered samples.

Table 4. Verification of samples for normality for the value-orientation criterion

\begin{tabular}{|l|c|c|}
\hline \multicolumn{5}{|c|}{ Before the experiment } \\
\hline \multicolumn{1}{|l|}{} \\
\hline Indicator & $C G(26)$ & $E G(24)$ \\
\hline Assim. $\left(S_{k}\right)$ & 0.581748 & 0.511168 \\
\hline Excess $\left(E_{x}\right)$ & 0.252049 & -0.099401 \\
\hline Math.exp. $(x)$ & 0.542308 & 0.547917 \\
\hline Median $\left(M_{e}\right)$ & 0.5 & 0.525 \\
\hline St.dev. $(S)$ & 0.128602 & 0.150708 \\
\hline Kvar $(V)$ & 0.237138 & 0.275056 \\
\hline$x+-S$ & $73.08 \%$ & $66.67 \%$ \\
\hline$x+-2 S$ & $92.31 \%$ & $95.83 \%$ \\
\hline$x+-3 S$ & $100.00 \%$ & $100.00 \%$ \\
\hline
\end{tabular}$\quad$\begin{tabular}{|l|c|c|c|}
\hline Assim. $\left(S_{k}\right)$ & 0.356661 & -0.14781 \\
\hline Excess $\left(E_{x}\right)$ & -0.12787 & -0.05496 \\
\hline Math.exp. $(x)$ & 0.553846 & 0.61875 \\
\hline Median $\left(M_{e}\right)$ & 0.525 & 0.6 \\
\hline St.dev. $(S)$ & 0.13109 & 0.100879 \\
\hline Kvar $(V)$ & 0.23669 & 0.163037 \\
\hline$x+-S$ & $69.23 \%$ & $70.83 \%$ \\
\hline$x+-2 S$ & $96.15 \%$ & $95.83 \%$ \\
\hline$x+-3 S$ & $100.00 \%$ & $100.00 \%$ \\
\hline
\end{tabular}


Table 5. Verification of samples for normality for the cognitive criterion

\begin{tabular}{|l|r|r|}
\hline \multicolumn{3}{|c|}{ Before the experiment } \\
\hline \multicolumn{1}{|c|}{ Indicator } & \multicolumn{1}{|c|}{$K \Gamma(26)$} & \multicolumn{1}{c|}{$\epsilon \Gamma(24)$} \\
\hline Assim. $\left(S_{k}\right)$ & 0.054367 & -0.299141 \\
\hline Excess $\left(E_{x}\right)$ & 0.313417 & 0.118258 \\
\hline Math.exp. $(x)$ & 0.623077 & 0.61875 \\
\hline Median $\left(M_{e}\right)$ & 0.625 & 0.625 \\
\hline St.dev. $(S)$ & 0.152467 & 0.119612 \\
\hline Kvar $(V)$ & 0.2447 & 0.193313 \\
\hline$x+-S$ & $73.08 \%$ & $75.00 \%$ \\
\hline$x+-2 S$ & $92.31 \%$ & $95.83 \%$ \\
\hline$x+-3 S$ & $100.00 \%$ & $100.00 \%$ \\
\hline
\end{tabular}

\begin{tabular}{|l|r|r|}
\hline \multicolumn{3}{|c|}{ After the experiment } \\
\hline \multicolumn{1}{|c|}{ Indicator } & $K \Gamma(26)$ & \multicolumn{1}{c|}{$\epsilon \Gamma(24)$} \\
\hline Assim. $\left(S_{k}\right)$ & 0.118966 & 0.075288 \\
\hline Excess $\left(E_{x}\right)$ & 0.402022 & 0.370542 \\
\hline Math.exp. $(x)$ & 0.640385 & 0.664583 \\
\hline Median $\left(M_{e}\right)$ & 0.65 & 0.65 \\
\hline St.dev. $(S)$ & 0.140014 & 0.101595 \\
\hline Kvar $(V)$ & 0.21864 & 0.15287 \\
\hline$x+-S$ & $69.23 \%$ & $70.83 \%$ \\
\hline$x+-2 S$ & $92.31 \%$ & $91.67 \%$ \\
\hline$x+-3 S$ & $100.00 \%$ & $100.00 \%$ \\
\hline
\end{tabular}

Table 6. Verification of samples for normality for the communicative-activity criterion

\begin{tabular}{|l|r|r|}
\hline \multicolumn{3}{|c|}{ Before the experiment } \\
\hline \multicolumn{1}{|c|}{ Indicator } & \multicolumn{1}{|c|}{$K \Gamma(26)$} & \multicolumn{1}{c|}{$C \Gamma(24)$} \\
\hline Assim. $\left(S_{k}\right)$ & -0.04143 & -0.472294 \\
\hline Excess $\left(E_{x}\right)$ & 0.237139 & 0.045227 \\
\hline Math.exp. $(x)$ & 0.642308 & 0.608333 \\
\hline Median $\left(M_{e}\right)$ & 0.65 & 0.6 \\
\hline St.dev. $(S)$ & 0.150128 & 0.118566 \\
\hline Kvar $(V)$ & 0.233732 & 0.194904 \\
\hline$x+-S$ & $69.23 \%$ & $70.83 \%$ \\
\hline$x+-2 S$ & $92.31 \%$ & $95.83 \%$ \\
\hline$x+-3 S$ & $100.00 \%$ & $100.00 \%$ \\
\hline
\end{tabular}

\begin{tabular}{|l|r|r|}
\hline \multicolumn{3}{|c|}{ After the experiment } \\
\hline Indicator & $K \Gamma(26)$ & \multicolumn{1}{c|}{$\epsilon \Gamma(24)$} \\
\hline Assim. $\left(S_{k}\right)$ & -0.21556 & -0.14993 \\
\hline Excess $\left(E_{x}\right)$ & -0.02173 & 0.206992 \\
\hline Math.exp. $(x)$ & 0.638462 & 0.672917 \\
\hline Median $\left(M_{e}\right)$ & 0.65 & 0.675 \\
\hline St.dev. $(S)$ & 0.132897 & 0.105273 \\
\hline Kvar $(V)$ & 0.208151 & 0.156443 \\
\hline$x+-S$ & $65.38 \%$ & $70.83 \%$ \\
\hline$x+-2 S$ & $96.15 \%$ & $91.67 \%$ \\
\hline$x+-3 S$ & $100.00 \%$ & $100.00 \%$ \\
\hline
\end{tabular}

As can be noticed in Table 4, the values seven items We used Student's t-test to test the hypothesis of statistically significant differences in the level of

competence of students before and after the experiment. Tables 7-9 show the results of the hypothesis test for three different criteria.

Table 7. Hypothesis testing for the value-orientation criterion

\begin{tabular}{|c|c|c|c|}
\hline \multicolumn{2}{|c|}{$C G$} & \multicolumn{2}{|c|}{$\overline{E G}$} \\
\hline$M_{d}$ & 0.011538462 & $M_{d}$ & 0.070833333 \\
\hline $\begin{array}{c}\text { Sum of } \\
\text { sq. }\end{array}$ & 0.061538462 & $\begin{array}{c}\text { Sum of } \\
\text { sq. }\end{array}$ & 0.234583333 \\
\hline$\sigma_{d}$ & 0.049613894 & $\overline{\sigma_{d}}$ & 0.100991462 \\
\hline$t$ & 1.19 & $t$ & 3.43604341 \\
\hline$t_{c r}$ & 2.056 & $t_{c r}$ & 2.064 \\
\hline
\end{tabular}

Table 8 . Testing the cognitive criterion hypothesis

\begin{tabular}{|c|c|c|c|}
\hline \multicolumn{2}{|c|}{$C G$} & \multicolumn{2}{|c|}{$E G$} \\
\hline$\overline{M_{d}}$ & 0.017307692 & $\overline{M_{d}}$ & 0.045833333 \\
\hline Sum of sq. & 0.239711538 & Sum of sq. & 0.249583333 \\
\hline$\sigma_{d}$ & 0.09792069 & $\sigma_{d}$ & 0.10417029 \\
\hline$t$ & 0.901262652 & $t$ & 2.155476002 \\
\hline$t_{c r}$ & 2.056 & $t_{c r}$ & 2.064 \\
\hline
\end{tabular}


Table 9. Hypothesis testing for the communicative-activity criterion

\begin{tabular}{|c|c|c|c|}
\hline \multicolumn{2}{|r|}{$C G$} & \multicolumn{2}{|c|}{$E G$} \\
\hline$M_{d}$ & -0.003846154 & $M_{d}$ & 0.064583333 \\
\hline Sum of sq. & 0.264615385 & Sum of sq. & 0.332395833 \\
\hline$\overline{\sigma_{d}}$ & 0.10288156 & $\overline{\sigma_{d}}$ & 0.120216441 \\
\hline$t$ & -0.190623213 & $t$ & 2.631856523 \\
\hline$t_{c r}$ & 2.056 & $t_{c r}$ & 2.064 \\
\hline
\end{tabular}

For all three criteria, the hypothesis of statistically significant differences in the levels of communicative competence of students before and after the experiment was confirmed for the experimental group and not confirmed for the control group. The parametric analysis of the results obtained using Student's t-test for related populations, confirmed our hypothesis for each of the criteria, and therefore, the introduction of thematic online debates in distance learning gave a positive result, the study was effective.

\section{Discussion}

Thus, the potential of the method of student thematic online debates for the development of professional competencies in future specialists was revealed as a result of the pedagogical experiment. Our findings are similar to author [26]. The study confirmed that the inclusion of students in an active position provides a method of debate in solving educational and professional problems, which significantly increases the level of communicative competence and quality of education in general. The effectiveness of the debate, as defined by authors [27] is consistent with self-determination and relevant theories of learning and the available literature on their use as a pedagogical tool. The results of the experiment proved the hypothesis of the study.

The research hypothesis that using the method of student thematic online debates can have a positive effect to increase the level of professional competencies of the future specialist was confirmed both by quantitative (its indicators are given in the previous paragraph) and by qualitative analysis of experimental results. In particular, a group of independent experts who were involved in assessing the effectiveness of the use of debate as a method of teaching within the distance format of the educational process, at the final discussion summarized that Debate is a way to form a student as a speaker. In addition, at the same time the path to an active position in life. The ability to publicly prove one's opinion, choose one's own way of solving a certain problem and convince others of its expediency is very necessary in modern life for a person who is not indifferent - both an adult and every child.

Debate is a tool for developing critical thinking and speaking skills. Greater results, however, will be achieved by those who learn to find contradictions in topics, build arguments protected from attacks, seek and find support for them, but also listen carefully to counter-arguments and think about answers. In other words, this result is achieved by those students who think independently. While estimating the success of acting in the framework of online debats the experts paid attention exactly of the highlighted criteria.

Using the method of student thematic online debates, students can develop the following competencies: willingness to work in a team, the ability to generalize, analyse and adequately perceive information, the ability to communicate in accordance with language norms, reasoned and clear oral and written speech. The study by authors [26] also found that discussion helps to develop the skills necessary for effective interaction both in the professional sphere and in everyday life, develop the ability to think critically, the ability to work in a team and focus on the essence of the problem. The results obtained by authors [27, 28] proved that debate is a favourable pedagogical technique for improving argumentation skills.

There are certain features of using the method of student thematic online debates in the course of distance education. When assigning roles, the teacher must take into account the language training and psychological characteristics of students. Students, for their part, do not always show sufficient demands and fairness in communicating with partners. During debates, participants do not always know how to control their emotional state, especially in conflict situations, to respond flexibly to various unforeseen turns during the game.

Debate is a modern and effective method of organizing online learning. The application of this method is effective because it allows you to successfully apply the acquired theoretical 
knowledge, consolidate the skills to freely conduct dialogues and discussions on a given professional topic.

Due to the variety of debate formats, they can be used at different stages of learning and in any area of student training. This pedagogical technology increases students' motivation to learn language independently and encourages conscious action in communicative situations, as debate improves declarative ability, argumentative ability, idealistic moral judgment, and realistic moral judgment [29, 30].

The debate method develops critical thinking [31], it helps students learn to act in the interests of the group, show respect for the views of interlocutors, be able to defend their opinions, which contributes to team building. Our conclusions are also confirmed by the conclusions of Mitchel et al. [14]. Future specialists learn to make decisions, understand problems, navigate in the information world through this method.

The success of a debate is largely determined by a topic that incorporates at least two conflicting positions. The teacher carefully think through the tasks of the dispute, anticipates possible options and, most importantly, the conclusions that students should come to as a result of the discussion. However, we agree with authors [32, 33] that the peculiarity of the discussion is that it is not necessary to find a final solution to the problem. In pedagogical terms, it is extremely important when choosing the topic of debate to ensure that the subject of the conversation was quite serious, encouraged participants to think, to the desire to find the truth. The purpose of debates is to create an indicative background for creative research and independent decisions.

It is believed that no less important role in the organization of experimental research was played by the introductory theoretical and practical training, which was conducted for students of the experimental group. Since these are first- and second-year students who became respondents in the current study, it was extremely important to explain to them the essence of the debate as a way of interaction. In preparation for the experiment and summarizing its results, we also widely used the methodology of debate, which is disseminated by IDEA (International Debate Education Association), which is the center of strategy, concept and forms of debate for young people. Karl Popper.

The uniqueness of the useful effect of the debate for the education of students of higher education is due to the fact that it is a curriculum of in-depth knowledge of the world; conflict-free problem solving program; training in democratic procedures and tolerance; preparation of program participants for public activities; program of extracurricular organization of student youth; program of intellectual competitions.

\section{Conclusions}

Distance learning is a modern pedagogical technology, which has become increasingly relevant during the pandemic. Reforming the education system to an online format provides for the search for new alternative and effective technologies for organizing the educational process. One of the problems of distance communication is the formation of communicative competence of a future specialist - a component of professional competence.

The modern world is dialogical in nature. The reasons for such dialogue are the cognitive and emotional interest of man, the need to transmit and perceive information, the need for constant communication with certain objects, actions, processes.

Thus, an information and communication field is created, in which we are all. A person can open wide horizons for his thoughts and actions, if he is ready for joint reflection, for dialogue. Dialogue means creating something new when everyone wins. Debates as a method allow you to master the skills of public speaking, analytical and critical thinking, learn to present your point of view in a structured and reasoned way, the opportunity to develop students' leadership qualities. However, perhaps the most important functional and professional role of debate for distance learning is to stimulate activity and motivation of students.

The study gave grounds to conclude that the method of debate is an effective approach to the organization of online learning, which allows to obtain not only theoretical knowledge, but also the possibility of applying them in professional activities in the future. Debates can be used as an educational technology that will not only promote maximum interest of students in the material, but also help to develop a number of special skills, such as: experience of rational behaviour in conflict situations, oral and public speaking skills, selfconfidence, ability to quickly navigate the situation and defend their point of view.

Participants develop the skills necessary for effective communication through debate. Thematic online debates provide: active involvement of the applicant in higher education in the search for educational and cognitive activities, the organization 
of training based on intrinsic motivation; organization of joint activities, partnerships; provide dialogic communication between the teacher and students in the process of acquiring new knowledge. Proof of the effectiveness of the proposed model of using debate within distance learning is confirmed by the unequivocally positive dynamics in the experimental group to improve the Valueorientation criterion, Cognitive criterion Communicative-activity criterion (in particular, at a high level of $13.79 \%, 7.38 \%, 11.56 \%$ respectively).

The research materials can be used by teachers in the development of distance online courses, guarantors of educational programmes, heads of departments for coordination of distance learning in higher educational institutions, methodological centres for organizing master classes, refresher courses. etc.

The current study focuses on the quantitative and qualitative determination of the impact of online debate methods on the communicative competencies of students of agricultural universities. We consider the study of the effectiveness of thematic online debates to increase the level of motivation to train future specialists as a prospect for further research. But it is equally important to determine how this method affects the acquisition of subject professional competencies. This may become a prospectus for further research. It would also be a good idea to organize group research and organize team debates between students based on a comparison of agricultural research results. The overall success of the study also prompts the idea of organizing and systemizing methodological materials and publishing a manual on the use of online debates as a form of organization of educational activities for university students.

\section{References:}

[1] Seaman, J. E., Allen, I. E., and Seaman, J. Grade increase: Tracking distance education in the United States. Babson Survey Research Group, 2018. Available online: https://onlinelearningsurvey.com/reports/grad eincrease.pdf (accessed 9.10.2021).

[2] Pramono, Ch. A., Manurung, A. H., Heriyati, P., and Kosasih, W. Analysis of The Influence of Entrepreneurship Capability, Agility, Business Transformation, Opportunity on Start-Up Behavior In E-Commerce Companies, In Indonesia During The Covid 19 Pandemic", WSEAS Transactions on Business and Economics, Vol. 18, 2021, pp. 1103-1112.
[3] Chernova, V. Yu., and Degtereva, E. A. Forecast of Development of the Dual-Use Industrial Products Market, WSEAS Transactions on Business and Economics, Vol. 17, 2020, pp. 987-992. https://doi.org/10.37394/23207.2020.17.97

[4] Eldar, A. G. Problems of Financial and Investment Support Modelling of the Regional Social and Economic Development, WSEAS Transactions on Business and Economics, Vol. 17, 2020, pp. 741-752. http://dx.doi.org/10.37394/23207.2020.17.72

[5] Faniran, T. S., Bakare, E. A., Potucek, R., and Ayoola, E. O. Global and Sensitivity Analyses of Unconcerned COVID-19 Cases in Nigeria: A Mathematical Modeling Approach, WSEAS Transactions on Mathematics, Vol. 20, 2021, pp. 218-234.

http://dx.doi.org/10.37394/23206.2021.20.23

[6] Erlina, Yu., and Elbaar, E. F. Impact of Covid-19 Pandemic on Local Rice Supply Chain Flow Patterns in Kapuas Regency, Central Kalimantan, Indonesia, WSEAS Transactions on Business and Economics, Vol. 18, 2021, pp.941-948. https://doi.org/10.37394/23207.2021.18.89

[7] Bakhov, I., Opolska, N., Bogus, M., Anishchenko, V., and Biryukova, Y. Emergency Distance Education in the Conditions of COVID-19 Pandemic: Experience of Ukrainian Universities, Education Sciences, Vol. 11, No. 7, 2021, p. 364. https://doi.org/10.3390/educsci1 1070364

[8] Fojtík, R. Problems of distance education, ICTE Journal, Vol.7, No. 1, 2021, pp.14-23.

[9] Zhou, L., Wu, S., Zhou, M., and Li, F. 'School's Out, But Class' On', The Largest Online Education in the World Today: Taking China's Practical Exploration During The COVID-19 Epidemic Prevention and Control As an Example, Best Evidence in Chinese Education, Vol. 4, No. 2, 2020, pp. 501-519.

[10] Alawamleh, M., Al-Twait, L. M., and AlSaht, G. R. The effect of online learning on communication between instructors and students during Covid-19 pandemic. Asian Education and Development Studies, 2020. Available online:

https://www.uwinnipeg.ca/remotehub/docs/effect-onlinelearningoncommunication-instructorstudent.pdf (accessed 9.10.2021).

[11] Albrahim, F. A. Online teaching skills and competencies, Turkish Online Journal of Educational Technology-TOJET, Vol. 19, No. 1, 2020, pp. 9-20.

[12] Mont, M. The Use of Debates in Higher Education Classrooms, Adult Education Research Conference, 2014. Available online: 
https://newprairiepress.org/aerc/2014/roundta bles/23 (accessed 7.10.2021).

[13] Rogers-Estable, M., Cavanaugh, C., Simonson, M., Finucane, T., and McIntosh, A. Effective Online Discussions. Virtual Learning Design \& Delivery, 2015. Available online. In: https://www.ck12.org/user:bWVzdGFibGUz N2VkdUBnbWFpbC5jb20./book/VirtualLearning-Design-and-Delivery/. ～(accessed 9.10.2021).

[14] Mitchel, E.T. Using debate in an online asynchronous social policy course, Online Learning, Vol. 23, No. 3, 2019, pp. 21-33. https://doi.org/10.24059/olj.v23i3.2050

[15] Smirnova, Z.V., Kamenez, N.V., Vaganova, O.I., Kutepova, L.I., and Vezetiu E.V. The experience of using the webinar in the preparation of engineering specialists, Amazonia Investiga, Vol. 8, No. 18, 2019, pp. 279-285.

[16] Abernathy, C. and Forestal, J. The Use of Debates in Political Science Courses, Journal of Political Science Education, Vol.17, No. 3, 2021, pp. 343-355, https://doi.org/10.1080/15512169.2019.16560 82

[17] Debate formats. Dem club, 2021. Available online: URL: http://www.debater.ru/ab2formats.htm (accessed 11.10.2021).

[18] Vaganova, O. I. Organization of practical classes in a higher educational institution using modern educational technologies, Amazonia Investiga, Vol. 8, No. 23, 2019, pp. 81-86.

[19] Vaganova, O.I., Konovalova, E., Abramova, N.S., Lapshova, A.V., and Smirnova, Z.V. Increasing the level of teachers' readiness for pedagogical project, Amazonia Investiga, Vol. 8, No. 22, 2019, pp. $286-294$.

[20] Ang, R. X., Chew, Q. H., Sum, M. Y., Sengupta, S., and Sim, K. Systematic review of the use of debates in health professions education-does it work? GMS journal for medical education, Vol. 36, No. 4, 2019. https://doi: 10.3205/zma001245

[21] Richardson, J. C., and Ice, P. Investigating students' level of critical thinking across instructional strategies in online discussions, Internet and Higher Education, Vol.12, No. 2, 2010, pp. 52-59. https://doi.org/10.1016/j.iheduc.2009.10.009

[22] Garrison, D. R., Anderson, T., and Archer, W. Critical thinking, cognitive presence, and computer conferencing in distance education,
American Journal of Distance Education, Vol. 15, No. 1, 2001, pp. 3-21. https://doi.org/10.1080/08923640109527071

[23] Weeks, P. P. Examining online debate and discussion, Academic Exchange Quarterly, Vol. 17, No. 1, 2013, pp. 55-59.

[24] Mutiaraningrum, I., and Cahyono, B. Y. Online debate in argumentative writing course: Potentials and challenges, International Journal of Language and Linguistics, Vol.2, No. 4, 2015, pp. 43- 54.

[25] Steuber, T. D., Andrus, M. R., Wright, B. M., Blevins, N., and Phillippe, H. M. Effect of Interprofessional Clinical Debates on Attitudes of Interprofessional Teams, PRiMER: Peer-Review Reports in Medical Education Research, Vol.5, 2021. https://doi.org/10.22454/PRiMER.2021.15414 9

[26] Vaganova, O. I., Tsyganova, L. V., Chelnokova, E. A., Lapshova, A. V., and Turchina, L. A. Technology "Debate\&quot; as a tool for communicative competence development, Amazonia Investiga, Vol. 9, No. 27, 2020, pp. 367-375. https://doi.org/10.34069/AI/2020.27.03.40

[27] Chew, Q. H., Seet, X. Y., and Sim, K. Use of Debate as a Pedagogical Tool in Psychiatry Residency Teaching: A Cross-Sectional Study, Advances in Medical Education and Practice, Vol. 12, 2021, p. 871. https://doi.org/10.2147/AMEP.S320614

[28] el Majidi, A., Janssen, D., and de Graaff, R. The effects of in-class debates on argumentation skills in second language education, System, Vol. 101, 2021, p. 102576. https://doi.org/10.1016/j.system.2021.102576

[29] Malloy, J. A., Tracy, K. N., Scales, R. Q., Menickelli, K., and Scales, W. D. It's not about being right: Developing argument through debate, Journal of Literacy Research, Vol. 52, No. 1, 2020, pp. 79-100. https://doi.org/10.1177/1086296X19896495

[30] Cariñanos-Ayala, S., Arrue, M., Zarandona, J., and Labaka, A. The use of structured debate as a teaching strategy among undergraduate nursing students: A systematic review, Nurse Education Today, 2021, p. 104766.

https://doi.org/10.1016/j.nedt.2021.104766

[31] Nurakhir, A., Palupi, F. N., Langeveld, C., and Nurmalia, D. Students' views of classroom debates as a strategy to enhance critical thinking and oral communication skills, Nurse Media Journal of Nursing, Vol. 
10, No. 2, 2020, pp. 130-145. https://doi.org/10.14710/nmjn.v10i2.29864

[32] Ivanova, N. L., and Korostelev, A. A. The impact of competitive approach on students' motivation in sport, Amazonia Investiga, Vol. 8, No. 18, 2019, pp. 483-490.

[33] Oliinyk, O., Bilan, Y., Mishchuk, H., Akimov, O., and Vasa, L. The impact of migration of highly skilled workers on the country's competitiveness and economic growth, Montenegrin Journal of Economics, Vol. 17, No. 3, pp. 7-19, 2021. https://doi.org/10.1016/10.14254/18005845/2021.17-3.1.

\section{Creative Commons Attribution License 4.0} (Attribution 4.0 International, CC BY 4.0)

This article is published under the terms of the Creative Commons Attribution License 4.0

https://creativecommons.org/licenses/by/4.0/deed.en US 